\title{
Voter Turnout in European Parliament Elections: A Spatial Analysis
}

\author{
Nadia Fiorino \\ Nicola Pontarollo \\ Roberto Ricciuti
}

CESIFO WORKING PAPER NO. 5910

CATEgory 2: PuBlic CHOICE

MAY 2016
An electronic version of the paper may be downloaded
- from the SSRN website:
- from the RePEc website:
- from the CESifo website:
wWw.SSRN.com
www.RePEc.org
www.CESifo-group.org/wp




\title{
Voter Turnout in European Parliament Elections: A Spatial Analysis
}

\begin{abstract}
In European Parliament elections turnout rates, traditionally lower than in national parliamentary elections, decrease from one elections to the next, and show strong variations within and between countries. What explains this decline? Why are there such big differences between and within the EU member countries? This paper investigates these problems by analyzing the last four EP elections in the EU-13, for 156 regions. We first study the spatial features of turnout and subsequently test a Hierarchical Linear Model to assess the impact of some socio-economic, institutional and political factors on voter turnout. The results confirm the spatial dependence of data and indicate a significant role of compulsory voting, domestic political cleavages, and uncertainty on the labor market. No evidence is found that European financial transfers, GDP per capita or unemployment influence turnout. Finally, the oldest segment of population seems more prone to vote than the youngest part.
\end{abstract}

Keywords: European Parliament elections, voter turnout, subnational variation, Hierarchical Linear Model.

\author{
Nadia Fiorino \\ University of L'Aquila \\ L'Aquila / Italy \\ nadia.fiorino@univaq.it
}

\author{
Nicola Pontarollo \\ University of Milan Bicocca \\ Milan / Italy \\ nicola.pontarollo@unimib.it
}

\author{
Roberto Ricciuti \\ University of Verona \\ Verona / Italy \\ roberto.ricciuti@univr.it
}

This research was funded by the research program "Inequality and economic crises" within the project "Economic Crises and the Quality of Democracies in Europe" (PRIN project 2010WKTTJP_005). We thank Katharina Hofer and participants at the European Public Choice Conference 2016 (Freiburg) for comments. 


\section{Introduction}

European Parliament (henceforth EP) elections have traditionally recorded lower turnout with respect to national parliamentary elections. According to the theory of the 'second order elections' pioneered by Reif and Schmitt (1980), in EP elections the stakes are lower (or perceived as such) than in national elections and people feel more free in their electoral choices. In this perspective, it is not surprising that EP elections register lower rates of participation and, sometimes, unusual results. ${ }^{1}$

Empirical analyses on EP elections that investigated the determinants of turnout are largely based on cross-national samples (Mattila, 2003; Schmitt and Mannheimer, 1991; Blondel et al., 1997), if not on case studies (single election or single country). Regional level studies have been few in number and restricted to single country or single election (Sundstrom and Stockemer, 2015). Cross-country and cross-regional analyses make the implicit assumptions that countries and regions are positioned on their steady state equilibria values of turnout. However, a closer look at the data shows that the rates of participation as well as being low, are also decreasing. Although successive treaty amendments have expanded the powers of the European Parliament (see Hix et al., 2007), turnout declines, dropping from 62 percent of voters in the 1979 elections to 43 percent in 2009. From the 1999 elections onwards, more than half of EU citizens desert the ballot box. Fig. 1 illustrates the level of turnout across 156 European regions in the 1999, 2004, 2009 and 2014 elections respectively. The figure significantly denotes changes of the countries' and regions' level of turnout during the last four EP elections. It also shows the heterogeneity of the voting behavior within and between countries. This suggests that considering a single observation for each country involves a loss of information, and therefore may lead to incorrect statistical inferences. In addition, various variables that theoretical and empirical studies have analyzed as determinants of electoral turnout, such as population density or income development (per capita GDP) are not homogeneous within the same country and vary over time.

\footnotetext{
${ }^{1}$ One of the most striking examples were the European and General Elections in the UK in 2014 and 2015. In 2014 turnout was 34.2\%, UKIP, Labour and Conservatives got 27.5\%, 25.4\% and 23.9\%, respectively (http://www.bbc.com/news/events/vote2014/eu-uk-results), whereas one year later turnout was 66.1\%, and the three parties got 12.6, 30.4, and 36.9, respectively (http://www.bbc.com/news/election/2015/results).
} 
In this perspective, as it makes sense to believe that turnout is lower in less salient elections, the key question is what explains the decline of the turnout? Why are there such big differences in turnout between and within EU member countries?

This paper tries to investigate these problems focusing on the last four EP elections (1999, 2004, 2009 and 2014) in the EU-13, for 156 regions, and exploiting the geographical features of voter turnout. The spatial analysis of turnout shows both a strong variation between countries and a tendency toward diminishing variation within countries. These results lead us to assess the impact of some socio-economic, institutional and political factors testing a Hierarchical Linear Model (HLM). Using a multi-level modelling indeed allows to consider a number of both national- and regional-level factors that might influence electoral participation and explain regional differences in turnout.

Building on the theory on voter participation, empirical studies of EP elections over the past decades suggest a number of determinants of turnout related to the European Union as well as to the national system. As theory on turnout has little to say about the relationship between economic adversity and voter participation, these studies give scarce attention to the role of economic hardship. The sample period we analyze is characterized by a decrease in employment levels as well as by a growing relevance of the legislative functions of the EP. These events signal the EP as a crucial decision-making body on economic policies of the member states. We expand the traditional set of variables that the numerous empirical studies on EP elections consider and analyze two indicators related to labor market (an indicator of employment protection legislation and the rates of unemployment) as markers of effective economic governance.

The rest of the paper is organized as follows. Section 2 provides a survey of the literature on the link between turnout and its determinants in EP elections. In Section 3 we analyze the dynamics of the EP elections in our sample, the variables, and the empirical strategy. Section 4 illustrates the results. Finally, in Section 5 we discuss the relevance of our findings.

\section{Determinants of voter turnout}

According to the Downs 'calculus of voting model' (1957), voters are rational agent that weigh costs and benefits of casting a ballot. Political scientists and economists have suggested that socioeconomic environment as well as political and institutional characteristics of a country might affect costs and benefits of voting, and therefore electoral participation. The extant empirical 
research has established some robust patterns, mainly concentrating on cross-countries differences or on a single case study.

Institutional variables and turnout. The primary focus of these cross-national studies has been on the impact of institutional variables. In this respect, compulsory voting, registration requirements and the type of electoral system have been considered to affect the conduct (costs) and outcome (benefits) of elections. While compulsory voting is associated with higher levels of turnout because it increases the probability of getting caught not-voting (Franklin, 2002; Blais and Dobrzynska, 1998; Jackman, 1987), registration requirements discourage electors since they amplifies the time, the effort and the information costs of voting (Rosenstone and Wolfinger, 1978). In addition, the electoral rules may influence voters' participation. Specifically, proportional representation systems (PR) are associated with higher levels of turnout in advanced democracies (Franklin, 2002; Jackman and Miller, 1995; Blais and Carty, 1990) as well as in post-communist countries (Kostadinova 2003). The effect of PR on voter turnout diminishes as the level of disproportionality increases (Blais and Dobrzynska, 1998) and the pattern is ambiguous when the analysis moves beyond well-established democracies (Fornos et al., 2004).

Various theoretical arguments support the role of PR in stimulating voter turnout. Under majoritarian systems, the disproportionality between votes and seats is larger than in proportional representation. This results in lower incentives to go to the polls since electors, especially when supporters of small parties, might consider wasted their vote (Jackman, 1987). Further, PR makes the elections more competitive. In each district, most parties have a chance to win at least one seat, and therefore have an incentive to mobilize everywhere (Jackman, 1987). Finally, PR produces more parties. The presence of multi-party politics provides a wider choice for voters, increasing the probability for an individual voter to find a political platform reasonably close to own opinions. This theoretical point, however, does not find empirical confirmation. As we point out in the following, almost all empirical investigations suggest that a higher number of parties reduces political participation (Jackman 1987; Blais and Carty 1990; Jackman and Miller 1995; Blais and Dobrzynska 1998; Radcliff and Davis 2000; Kostadinova 2003). These empirical findings thus exclude that PR increases turnout via the (higher) number of parties it produces.

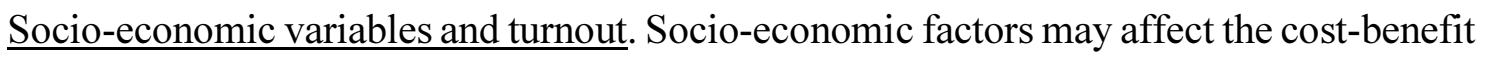
of voting and, as such, cross-national variations in turnout. In more developed countries people are more informed and have more resources (including time) to devote to politics. This may well amplify the political involvement of citizens and stimulate voter turnout (Oppenhius, 1995; Verba et al., 1995). Empirical evidence supports that turnout is higher in more advanced and richer 
countries and exceptionally higher in very small countries (Blais and Dobrzynska 1998, Fornos et al., 2004).

There is surprisingly little research investigating the effects of economic performance on voter participation. In contrast with the dominant conclusion that poor economic performance reduces voter turnout, inhibiting incumbent accountability for bad performance (Redcliff, 1992, 1994), recent research theorize and verify that unemployment rates will increase voter turnout (Burden and Wichowsky, 2012).

The size and the concentration of the population has also been linked to variations in turnout. Voters living in larger communities are less likely to consider their vote to be decisive to the outcome of the election. This decreases the benefits from voting (Geys, 2006; Blais and Dobrzynska, 1998). The predictions of the theory diverge on the direction of the relationship between population density and turnout. Population concentration may decrease voter turnout that develop more easily in relatively low-density areas where community relations are closer and more direct, and politics more personal (Overbye, 1995). In contrast with this view, another theory suggests that in countries with higher population densities, electors are more concentrated and easier to mobilize (Lipset, 1981). As expected from the contradictory theoretical explanations, the existing empirical studies do not find unanimous support for either of the two perspectives (see on this point Geys, 2006). Finally, many studies have shown that oldest segments of population with respect to youngest people tend to participate more in most form of political activity (see among others Powell, 1986).

Political variable and turnout. Literature has also analyzed the role of parties' system in explaining cross-countries variation of turnout. Most research incorporates the number of parties. Nevertheless, this variable may have contradictory consequences, thus it is not clear whether we should expect the correlation of turnout with the number of parties to be positive, negative, or nonexistent (Geys, 2006). On the one hand, as observed before, turnout should be higher the more parties there are. Moreover, the more parties there are, the greater the electoral mobilization (Jackman, 1987). On the other hand, as Jackman (1987) suggests, multi-party systems usually produce coalition governments, which make elections less decisive because the selection of the government depends on the backroom agreements among parties (Downs, 1957). This suggests the opposite hypothesis that the greater the number of parties, the lower the turnout.

While almost all empirical research has found a negative correlation between the number of parties and turnout (Jackman 1987, Blais and Carty 1990, Jackman and Miller 1995, Blais and Dobrzynska 1998, Radcliff and Davis 2000, Kostadinova 2003), the view that a higher 
number of parties reduces turnout because they produce coalition governments (and elections are therefore less decisive) is not empirically supported (Blais and Carty, 1990; Blais and Dobrzynska, 1998).

The role of the competitiveness of the political arena has also been investigated in terms of closeness of electoral outcomes variable (the so-called Downsian closeness hypothesis). In a rational choice perspective the closer the election is, the greater the likelihood that one vote affects the outcome of the election, thus the higher the turnout (Powell 1986). Another argument suggests that a close election ought to trigger higher campaign activities by parties, which in turn should additionally push voters to actually cast their ballots (Geys 2006). Empirical evidence shows that the impact of a close election (and by implication, the impact of lack of competition) on electoral participation when confirmed, is markedly small (Blais, 2000; Blais and Dobrzynska, 1998).

EP elections and turnout. Within the wide body of empirical literature on turnout, attention on EP elections has produced a number of empirical studies (Blondel et al., 1997) aimed at explaining the lower rates of turnout that characterizes EP elections relative to national parliamentary elections. Although the theoretical background normally used is related with the 'general' literature on turnout, some theoretical propositions are more directly related to the EP specific framework.

The most famous explanation on EP elections is the so-called 'second-order national election' theory (Reif and Schmitt, 1980), which is rooted in theories of midterm elections in the United States. This theory is based on two key arguments. National political arena conditions and dominates the EP elections because the latter occur at different timing relative to the domestic 'electoral cycle'. Strictly linked to this argument, the second key proposition is that people vote differently (i.e., people may vote or abstain) in 'second-order' EP elections because less is 'at stake' compared to the 'first-order' national parliamentary elections. Various empirical studies give support to this model, showing that turnout is lower than in national elections, smaller parties perform better, and parties in national government are punished, particularly during the midterm (van der Eijk and Franklin 1996; Marsh 1998; Hix and Marsh, 2011). These patterns of behavior are generally interpreted as signal of lower salience of EP elections.

We also know quite well that institutional context matters. It does make a difference whether voting is compulsory or not and whether or not it is restricted to Sundays (van der Eijk and Franklin, 1996). When the rule is enforced, compulsory voting increases the costs of not 
voting, leading to higher turnout rates, while having elections on Saturday or on Sunday lowers the costs of voting since on weekdays people follow their daily routines.

Most of these studies focus on a single country or on single elections; cross-countries analyses are conducted at the national level, which makes it hard to capture the differences on electoral participation within a country. Although the political science literature has noted the importance of the space on turnout (Cho and Rudolph, 2008), the analyses based on regional level data are scarce and restricted to single countries or to single election. Sundstrom and Stockemer (2015) is the only study that analyzes European regions. The authors focus on the relationship between the quality of government and electoral participation using cross section methodology and thus neglecting the important variations that turnout (and its potential determinants) shows within and between European countries over time (which means in the different elections). Nevertheless, understanding electoral participation in general has to take contextual factors that vary over time. This is what this paper aims at doing.

\section{Empirics}

\subsection{The dynamics of turnout in Europe}

Turnout at EP elections will be initially analyzed to identify its spatial dynamics and the possible tendency to form identifiable clusters. The data on turnout are taken from the European Election Database and national sources and regard four elections: 1999, 2004, 2009 and 2014 in the EU13, for 156 regions. $^{2}$ We consider Portugal, Spain, France, Belgium, Luxemburg, Netherlands, Denmark, UK, Ireland, Germany, Italy, Greece, and Austria and exclude Finland and Sweden because of the difficulty to collect data for 2014 elections. To analyze space dependence, the most known indicator is the Moran's I (MI) (Moran, 1950). This statistics has been widely used in the literature to describe economic phenomena whose distribution in the space is not random (Le Gallo and Ertur, 2003; Ertur et al. 2006; Dall'Erba, 2005; Gregory and Patuelli, 2015).

The $M I$ relates the value of a selected variable with the values of the same variable in the neighbor areas, namely its spatial lag. The intuition behind is that socio-economic phenomena might be not isolated in space and what is happening in a certain location might be correlated to what is happening in the neighbor locations. The formal definition of this relation is as follows:

\footnotetext{
${ }^{2}$ Greece is considered a single region because of the lack of data for 2014. In the other cases, we refer to NUTS-2 regions, with the exception of Great Britain, Spain and Germany where NUTS-1 regions are used.
} 


$$
M I=\frac{N}{\sum_{i} \sum_{j} w_{i j}} \frac{\sum_{i} \sum_{j} w_{i j}\left(x_{i}-\bar{x}\right)\left(x_{j}-\bar{x}\right)}{\sum_{i} w_{i j}\left(x_{i}-\bar{x}\right)}
$$

where $N$ is the number of regions indexed by $i$ and $j, x$ is the variable of interest; $\bar{x}$ is its mean, and $w_{i j}$ is an element of the spatial weights matrix $W_{i j}$, which is defined as a queen contiguity matrix, i.e. regions are considered as neighbor if they touch theirselves for at least a point. ${ }^{3}$ Then, as customary, the matrix is the standardized by row.

The calculated $M I$ for global autocorrelation varies between -1 and 1 . A positive coefficient points to positive spatial autocorrelation, i.e. clusters of similar values can be identified. The reverse represents regimes of negative association, i.e. dissimilar values clustered together in a map. A value close to zero indicates a random spatial pattern.

One of the advantages of this statistics is that it can be visualized in a scatterplot, the socalled Moran scatterplot, in which the spatial lag of the (standardized) variable is on the vertical axis and the original (standardized) variable is on the horizontal axis. Thus, each of the points in the scatterplot represents a combination of a locations' value and its corresponding values in the surrounding regions, i.e. the spatial lag. The $\mathrm{x}$ - and $\mathrm{y}$-axes divide the scatterplot into 4 quadrants (anticlockwise from top right): in the first and third (high-high, HH, and low-low, LL, respectively) a location that exhibits a high (low) value of the variable is surrounded by locations with a high (low) value of the variable as well. In the second and fourth (low-high, LH, and highlow, HL, respectively) a location with a low (high) value of the variable is surrounded by locations with a high (low) value of the variable. A concentration of points in the first and third quadrants means that there is a positive spatial dependence (nearby locations will have similar values), while the concentration of points in the second and fourth quadrants reveals the presence of negative spatial dependence (that is, nearby locations will have dissimilar values).

Figure 1 shows the quartiles of turnout in the considered years on the left side, and the Moran scatterplot on the right side. The maps display that turnout has a strictly national pattern and a consequent strong spatial autocorrelation for each period. There are countries like Italy and Greece that exhibit high levels of turnout during the whole period, while others, like Belgium and Great Britain, where turnout is very low. Between these two extremes there is a set of less homogeneous countries. From the least to the most homogeneous, there are Spain, France and

\footnotetext{
${ }^{3}$ The islands have been connected to the nearest region.
} 
Germany. Mediterranean countries have the highest turnout, although in the last two elections they are much closer to the EU average than before. The Moran scatterplots confirms the situation the maps depict. The positive slope and the concentration of points representing the regions in the first and third quadrant suggest that regions with high (low) turnout are clustered in space. The advantage of using Moran statistics and scatterplots instead of the simple representation in a map is that we have a statistically funded methodology that confirms the presence or absence of clusters of regions with similar or dissimilar values. In our case, on the top of the Moran scatterplot, we reported the Moran's I, which is quite stable and around the value of 0.60 . This means that there is spatial persistence over time, with well-defined clusters of regions characterized by high and low turnout, respectively. Nevertheless, a closer look at the points in the Moran scatterplot reveals that their distribution is much more widespread in 1999 than in 2014, with a group of regions, identified as those belonging to The Netherlands, steadily located in the upper part of the first quadrant. This, in spite of the quite stable value of the Moran's I, means that there is a changing pattern of EU turnout. Such pattern, while does not alter the relative ranking of EU regions in terms of turnout, makes them more similar over time. This is also confirmed by the values of the quartiles in the left-side maps. The lower quartile ranges between $38 \%$ and $42 \%$, while the last one steadily declines from $65.5 \%$ of 1999 to $52.3 \%$ of 2014 .

[Figure 1 about here]

A clearer visualization of the changing pattern of turnout over time is also shown in Figure 2 and 3. Figures 2 represents the boxplots for each year. The box in the middle of each boxplot describes central tendencies of a distribution, i.e. middle $50 \%$ of the distribution. The solid thick line inside the box locates the median; the top and bottom edges are the $75^{\text {th }}$ and $25^{\text {th }}$ percentiles, respectively. The height of the box is the inter-quartile range, IQR. The median turnout is relatively stable over the four elections, whereas the middle $50 \%$ of the cross-section distribution shrinks over time as well as the distance represented by the rays emanating from the middle box that represent the upper and lower adjacent values. The "whiskers" correspond, respectively, to the upper adjacent value, i.e of the largest turnout value observed no greater than the $75^{\text {th }}$ percentile plus $1.5 \times I Q R$, and to the lower adjacent value, i.e. the lower turnout value observed no smaller than the $25^{\text {th }}$ percentile minus $1.5 \times I Q R$.. Finally, the points, that lie outside the upper and lower adjacent values are outliers. The presence of outliers in the last three periods 
is coherent with what observed in the Moran scatterplot and refers to regions belonging to The Netherland. The figure, in spite of the tendency of turnout to be spatially more homogeneous along time, in few regions it continues to be rather high.

[Figure 2 about here]

Figure 3 shows the within and between country variation of turnout over time for countries with more than 2 regions. We observe that, in line with the previous analysis, the between variation is much larger than the within variation. In addition, with the exception of Italy, there is a clear decline in the variance of turnout, pointing to a more homogeneous spatial pattern both within and between countries.

[Figure 3 about here]

The results from the previous analysis support that the EP turnout is not stable over space and time. Also, despite the evolution of the geography of the participation to the vote, the spatial pattern is quite strong and strongly related to the country to which regions belong to. This suggests that a careful analysis of the determinants of EP elections needs to consider both context variables referred to the country level as well as more specific factors related to the regional dimension. The first set of variables would explain the relative spatial stability over time revealed by the Moran scatterplot and Moran's I, while the second the evolution in terms of the tendency of regions to a higher homogeneity within and between countries.

\subsection{Model specification, variables and methodology}

The model includes seven regional-level variables and eight national-level variables. The data typology, with two different geographical levels, leads to consider Hierarchical Linear Modelling (HLM) as a natural choice (Hox, 2010:1). This because HLM allows clustering regions within their countries to evaluate regional-level covariates' (so-called Level 1) effects within their national context (so-called Level 2 covariates), correcting for the non-independence of observations within countries (intra-class correlation) and avoiding an overestimation of the statistical significance of these Level 1 indicators (O'Connell and McCoach, 2008). A common problem with observations nested within a higher level is that there may be a problem of 
dependencies because regional turnout in the same country is likely to be similar in ways not fully accounted for by variables related only to regional scale included in a single-level model. Multilevel models have also the advantage of accommodating the spatial dependency of the residuals by differentiating between-individual errors from between-neighborhood errors (Orford, 2000). This dependency, if not considered, leads to biased standard error estimates (Snijders and Bosker, 1999). Our model departs from Sundstrom and Stockemer (2015) because we also exploit the time dimension of the data because considering a panel structure.

We assume that the turnout at the EP elections is affected by several factors, and we estimate the following regression:

$$
\text { Turnout }_{i t}=a_{0}+a_{1} \text { INST }_{i t}+a_{2} \text { SOCEC }_{i t}+a_{3} \text { DOMESTIC POLITICS }_{i t}+a_{4} \mathbf{E U}_{\mathrm{it}}+A_{\mathrm{n}}+A_{\mathrm{t}}+u_{i t}
$$

Where $i$ denotes the country or region, depending on the specification of the variable, and $t$ the election year $(1999,2004,2009,2014) . A_{\mathrm{n}}$ is the random intercept representing level 2 (country specific) residuals, $A_{\mathrm{t}}$ is the time specific random intercept residuals, and $u_{i t}$ are level 1 (regional specific) residuals. They are assumed to be mutually independent and normally distributed with zero mean and variance equal to $\sigma^{2}$. Level 2 residuals are assumed to be uncorrelated with $u_{i t}$, mutually independent and normally distributed with zero mean and variance equal to $\eta^{2}$ and $\tau^{2}$ for country and time specific, respectively. Fixed effects are expected to have a systematic and predictable influence on the data, while random effects can be expected to have a non-systematic, idiosyncratic, unpredictable influence on the data. Thus, random-effects give the structure to the error term. The variables can be described as follows:

1) Turnout, the dependent variable, is the number of votes in a country/region $i$ at election year $t$ as a share of the registered citizens. The data on this variable come from the European Election Database and from the Ministry of Interior of the considered countries.

2) INST is a vector of two institutional variables, Compulsory voting and Weekday vote, that have been largely explored in the literature (among others, Franklin, 2002). The connection between compulsory voting and higher voter turnout is self-evident. When the rule enforces turnout, the costs of not voting increases, leading to higher turnout rates. Also, having elections on weekdays increases the cost of voting since people follow their daily routines, decreasing electoral participation. The source of both these variables is the Ministry of Interior. 
3) The vector SOCEC includes some economic as well as socio-economic variables. $\log (\mathrm{per}$ capita GDP) is the logarithm del GDP pro capita in PPS, the usual indicator of economic development, to account for the literature that emphasizes the role of economic resources in stimulating the access to information and thereby political involvement of citizens and voter turnout (Powell, 1982). The source of these data is Eurostat Regional Database. ${ }^{4}$ To control for the labor market conditions we use Employment protection and Unemployment. Employment protection corresponds to the OECD indicators of employment protection. This variable is a synthetic indicator of 'the strictness of regulation on dismissals and the use of temporary contracts'. More specifically it measures the procedures and the costs involved in dismissing individuals or groups of workers and the procedures involved in hiring workers on fixed-term or temporary work agency contracts. For each year, indicators refer to regulation in force on January $1^{\text {st }}$ (source: OECD). We use this indicator to proxy the uncertainty on the market labor conditions. Unemployment is percentage of long-term unemployed over total unemployment (source: Eurostat Regional Database). The literature provides two competing theories regarding the expected relationship between turnout and the economy. Some scholars argue that people under economic adversity are encouraged to be more active politically (vote, protest, lobby...) and are more prone to vote to punish government's policies (Verba et al., 1995). Another theory maintains the opposite, assuming that voters respond to adverse economic conditions by withdrawing from the political process (Rosenstone, 1982). The vector also includes $\log$ (Density) that is the $\log$ of the number of inhabitants per square $\mathrm{km}$. We have no prior expectation regarding the sign of the coefficient associated with this variable since theoretical predictions are conflicting. On the one hand, attitudes that stimulate voter turnout develop more easily in relatively concentrated political environments where community relations are closer and more direct, thus a negative sign is expected (Oliver, 2000, among others). In contrast, another theory suggests a positive expected sign since in areas with higher population densities voters are more concentrated and easier to mobilize (Lipset, 1981). The source for this variable is Eurostat Regional Database for population and Cambridge Econometrics for regional areas. Finally, Dependency ratio, that is the percentage of people over 65 years over the young between 20 and 24 years, captures the influence of the age structure of the population on voter turnout (source: Eurostat Regio Database). The expected sign on this variable is positive.

\footnotetext{
${ }^{4}$ Due to data availability problems, we use the following years: 2000, 2004, 2009 and 2013.
} 
4) DOMESTIC POLITICS is a vector that includes Herfindahl_gov, Herfindahl_opp and Effective number of parties. Herfindhal indices measure the sum of the squared seat shares of all parties in the government (Herfindhal_gov) or in the opposition (Herfindhal_opp). These variables aim at capturing the fractionalization of the government and of the opposition, respectively (source: Beck et al., 2001). Alternatively, we use Effective number of parties, a variable mostly used in turnout literature, which weight the number of parties in the legislature by the relative strength measured as their vote share (source: Gallagher, 2015). All these variables aim at analyzing the fragmentation of the party system. ${ }^{5}$ As theoretically there is no consensus on whether political fragmentation can be expected to increase or decrease political participation, we do not have an a priori expectation on the sign of these variables.

A key problem in analyzing EP elections is their second-order nature, which fails to motivate voters in the elections themselves, or in politics at the European level more broadly (Reif and Schmitt, 1980; Van der Eijk and Franklin, 1996; De Vreese et al., 2006). The result is that vote choices are based on domestic, rather than European, policy concerns. In this perspective, European elections are useful as vehicles for transmitting information from voters to leaders. The proxy traditionally used to capture this issue is the time elapsed between national first order and EP second-order elections. We decided to do not use this kind of variable because the political structure of EU countries strongly varies and it is not always easy to disentangle among types of elections in terms of political importance and impact. ${ }^{6}$ At this regard, instead of the mentioned variable, we include Protest vote that is the difference between the sum of the percentage of the two major parties in the general elections immediately preceding the European elections and the sum of the percentage of the same two parties in the European elections (source: European Electoral Database and Ministry of Interior of the considered countries). This variable

\footnotetext{
${ }^{5}$ These variables build on empirical literature on political fragmentation that have concentrated on both government and opposition. The rationale is that for a given coalition is not the same to confront an opposition made up by one party or more than one party. A limited number of opposition parties may find it easier to coordinate to oppose government policies. If there is a large number of opposition parties, their interests may be divergent, and some of them may engage in bargaining with the coalition who support the government (see on this issue Ricciuti, 2004). Herfindahl_gov is index that divides the number of "other" seats by the number of "other" parties and uses this average for the size of the "other" parties. Herfindahl_opp is calculated in the same manner as the Herfindahl_gov (source: Beck et al., 2001).

${ }^{6}$ An example is the Italian case in which regional elections are often seen as a confirmatory step by government in office and, at this extent, have important consequences.
} 
aims at capturing the extent of protest voting as a difference with the results of general elections. Unsatisfied voters may abstain but may also send a message to more established parties by voting for outsiders in the second order EP elections. While our indicator is an ex post measure with respect to the time elapsed between national and EP elections, nevertheless it is a more satisfactory proxy of the different stakes characterizing the two kind of elections. This because it is built on the effective choices that voters made.

5) $\mathbf{E U}$ is a vector that includes variables related with the EU itself: Trust_EU and Objective1 regions. Trust_EU measures the trust in the European Parliament, where 0 means that you do not trust an institution at all, and 10 means you have complete trust (source: European Social Survey). ${ }^{7}$ Objective1 regions is a dummy variable equal to one if regions are below the $75 \%$ of EU GDP per capita and thus receive the majority of EU Structural Funds, 0 otherwise ${ }^{8}$. While in countries/regions that are large net contributors to the EU budget voters may think that the EU is financed with their tax money and this may lower their incentive to vote in EP elections, in countries/regions benefiting from the EU subsidies voters are more likely to mobilize (Mattila, 2003). Most of the countries are rather equally balanced between contributions and benefits, but some countries clearly stand out.

Although Bendor et al. (2003) and Fowel (2006) found that the turnout choice is related with the turnout choice of the previous election, we do not include a autoregressive term turnout among in the right-hand side of equation (2). First, first-differences in the GMM and the autoregressive term would have halved the number of elections and observation. Second, we could have not use the time invariants variables (compulsory voting, and dummy for objective1 regions). Third, finding viable internal instruments was a difficult task. However, fixed effect, introduced in the robustness checks, can alleviate this problem by taking into account idiosyncratic persistence for each country.

Table 1 presents the summary statistics and the territorial level of the variables, whereas Table A1 in the Appendix provides a correlation matrix.

\footnotetext{
${ }^{7}$ Data for Austria, Belgium, Denmark, France, Germany, Netherlands, Spain, Ireland and Great Britain are for years 2002, 2004, 2008 and 2012. Data for Greece regard 2002, 2004, 2008, and 2010, for Italy 2002, 2004 and 2012, for Luxemburg 2002 and 2004. In the case of Italy, data for 2004 are used instead of data for 2008, while for Luxemburg data for 2004 are used to proxy data for 2008 and 2012.

8 This dummy variable is built on the information available online (see http://ec.europa.eu/regional_policy/index.cfm/en/policy/evaluations/data-for-research/).
} 
[Table 1 about here]

\section{3 Results}

Our empirical strategy consists in estimating equation (1) adding stepwise the vectors of variables we consider. Table 2 reports our results. We find that some variables are highly significant, whatever the selected model. Looking at model 1, one can see that compulsory voting increases the costs of not voting, leading to higher turnout rates although no penalties are imposed for failure to comply, while having election during the week does not display effects on voter participation. Adding socio-economic and demographic variables (model 2) shows that neither per capita GDP, nor population density impact on voter turnout. Also Unemployment does not show significant effect on voter participation while Employment protection negatively affects turnout, decreasing the participation to the vote. Dependency ratio, is also significant, confirming that age structure of population matters in explaining variation in the electoral behavior of voters. Thus, the oldest segment of population with respect to youngest people is more prone to turn out.

[Table 2 about here]

Model 3 and $3 a$ include the variables capturing the influence of domestic politics. While a more concentrated government decreases electoral participation, the concentration of the opposition does not have any effect on voter turnout. Given the concentration (fragmentation) of government, a more concentrated opposition is probably more effective in opposing the government. This increases the confidence of voters in political system and thus the electoral participation.

Effective number of parties is used in model 3a as alternative to Herfindhal_gov and Herfindhal_opp. The results on this variable indicates that it is significantly and positively related to the dependent variable. Therefore, the higher the number of parties, the higher is voter turnout. The positive association between the effective number of parties and turnout could also be interpreted as an implicit signal that proportional representation could foster turnout because it produces more parties, thus providing voters with more choice and more mobilization. The results on Herfindhal_gov that turnout increases with higher fragmentation of government 
reinforce this interpretation since more fragmented governments are the results of proportional representation.

Protest vote is highly significant and positive. This allows thinking that the electors might decide to "punish" the most voted parties in the previous elections voting at EU parliament elections: the highest is the gap, the highest is the turnout. ${ }^{9}$

Model 4 and 4 a add the vector EU. While the variables previously considered maintain their significance and sign, trust on European parliament does not have any impact on turnout, as well as the regions that obtain the support from Cohesion Policy.

In order to check if the HLM is the appropriate choice, we can split the total variance by our nested effect variance to give us the proportion of variance accounted for, which indicates whether or not each random effect is meaningful. If all the percentages for each random effect are very small, then the random effects are not present and linear mixed modelling is not appropriate.

The variance of turnout conditional to the explanatory variables is equal to $\eta^{2}+\tau^{2}+\sigma^{2}$. Therefore, the overall conditional variability of turnout can be decomposed in two components: $\hat{\rho}_{\text {year }}=\eta^{2} /\left(\eta^{2}+\tau^{2}+\sigma^{2}\right)$ and $\hat{\rho}_{\text {country }}=\tau^{2} /\left(\eta^{2}+\tau^{2}+\sigma^{2}\right)$, known as the intraclass correlation coefficients and representing, respectively, the proportion of variability due to country and time clustering and measuring the correlation shared by units within the same country or in the same year.

[Figure 4 about here]

We can observe that the intraclass correlation coefficients for country random effects alone is quite substantial and ranges from $66 \%$ to $71 \%$. The total variability explained by yearly random effects is only around $1-5 \%$, so the nested effects related to time variable are not meaningful.

\footnotetext{
${ }^{9}$ Usually in Europe the two largest parties are the party in government and its main opposition and they alternate into power. If a voter wants to vote against them, he should vote for smaller parties. In some countries there are "grand coalitions" in which the two main parties rule together (usually Austria, more recently Germany), in this case voting for a party other than the two in government is the main way to convey a protest message against them (without deserting the polls).
} 
The intercepts for country random term, whose estimates are based on model 4, are reported in Figure 4. The intercept term varies between -0.159 and 0.159 and the standard deviation is equal to 0.104 . The positive values refer to Italy, The Netherland, Luxemburg, Ireland and Spain, which is coherent with the persistent high turnout over time in section 3.1. Between the other countries with negative intercept we have the countries with the lowest turnout plus Greece. The reason lies in the strong variation in EP election participation: from $71.5 \%$ in 1999 to $52.6 \%$ in 2009 to rise to $60 \%$ in 2014 .

\subsection{Robustness checks}

An alternative to multilevel approach, which can be problematic especially if we are in a country comparative analyses with few countries (Maas and Hox, 2005), is controlling for heterogeneity by means of dummy variables, thus avoiding for the omitted variable bias (Allison, 2009: 14).

Following Hox (2010: 13), the country specific error term in multilevel models is assumed to be normally distributed and independent of both the other variables in the model and the individual level error term. In fixed effects regression, being the country specific error term a set of fixed numbers estimated in the model, it is irrelevant whether or not the residuals are independent of the other variables in the model (Allison 2009: 21). The results of OLS regression with country and time dummy variables are presented in table 3 and corroborate our previous findings. The F-test on their joint significance confirm that both groups are significantly different from zero. We can note that the AIC statistics is typically lower in the multilevel estimation than in the OLS model, showing that the former outperforms the latter.

As a further robustness check, we consider only regional random effects and time dummies. The results are once again in line with our main findings. Finally, we estimate our model excluding countries composed by only one region (that is Greece, Denmark and Luxemburg), all together and one by one. We find no differences in terms of sign and significance with respect to the models presented in Table 2. These results, are not reported here but available upon request.

[Table 3 about here] 


\section{Concluding remarks}

This paper concentrates on the geographical features of voter turnout in the last four EP elections in the EU-13, for 156 regions. Indeed, a closer look at the data shows that turnout rates, traditionally lower than in national parliamentary elections, while are decreasing from one elections to the next, hide relevant variations over time as well as within and between countries. We find that the territorial distribution of turnout tends to have both space and time evolution. Regarding the space dimension, the relative spatial distribution of EU regions in terms of turnout does not vary, meaning that a region characterized by high (low) turnout and surrounded by regions with high (low) turnout in 1999 continues to have the same spatial pattern in the following elections. As far as time is concerned, we observe a stronger variability between rather than within countries over the whole period. This variability decreased over time making regions more similar in terms of turnout. Furthermore, while participation to EP elections is declining in regions belonging to Mediterranean countries, which historically have the highest turnout, it is increasing in the rest of the area.

The evidence emerged from the spatial analysis suggests that modelling the factors that explain the voter turnout in EP elections needs to consider both, regional- and national-level specification. The Hierarchical Linear Model (HLM) we use to assess the impact of some sociodemographic, economic, institutional and political factors on voter turnout shows that regionallevel turnout is strongly driven by some national-level covariates as well as by regional-level variables. Overall, our results indicates that oldest people, as the literature suggests, are more prone to turn out in EP elections with respect to the youngest part of the population. When the law enforces turnout, then voter participation increases although no penalties are associated with the abstention. The effectiveness of the EU and the economic performance of its countries do not show any significant impact. The financial EU transfers do not affect the participation in EP elections suggesting that probably they are not perceived as a direct result of the EU policy choices, rather as the results of local political decisions. No evidence is found that GDP per capita or unemployment influence turnout. Nevertheless, the uncertainty on labor market seems to decrease turnout. Most importantly, our results confirm that there is an interplay between the national and the European political scenario. It seems that more fragmented governments, which are generally the results of PR systems, increase turnout. The use of the alternative variable capturing the effective number of parties in legislature confirms that the presence of more parties is positively associated to voter turnout. This evidence indirectly show that proportional representation could foster turnout because it produces more parties, thus providing voters with 
more choice and more mobilization. Individuals who want to vote for small parties have more reason to turn out under PR. Moreover, everything else being equal, participation on EP elections is driven by a protest vote against the establishment.

Finally, the non-significance of the variable that accounts for the trust on European institutions suggests that turnout in EP elections is not affected by citizens' attitudes towards European institutions, and reinforce their 'second-order' nature. 
Figure 1: turnout of EU parliament elections

a) Quartiles map 1999

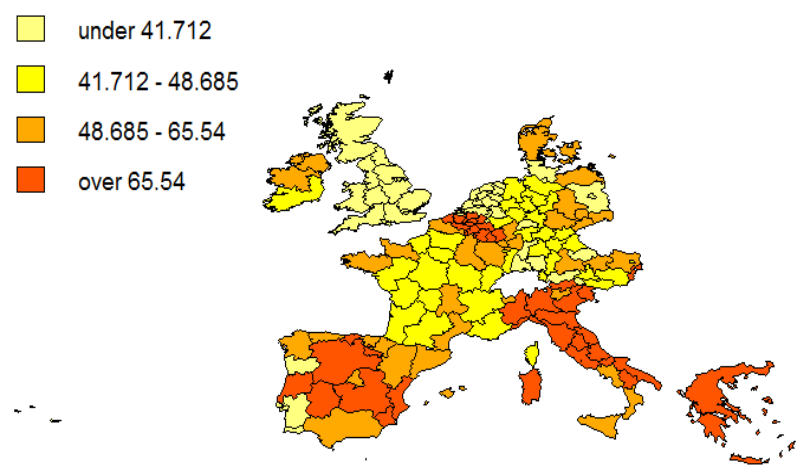

c) Quartiles map 2004

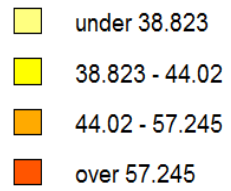

e) Quartiles map 2009

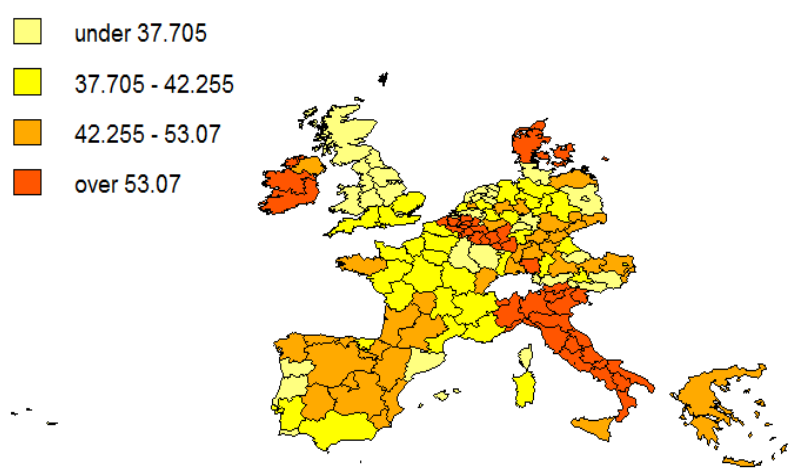

g) Quartiles map 2014

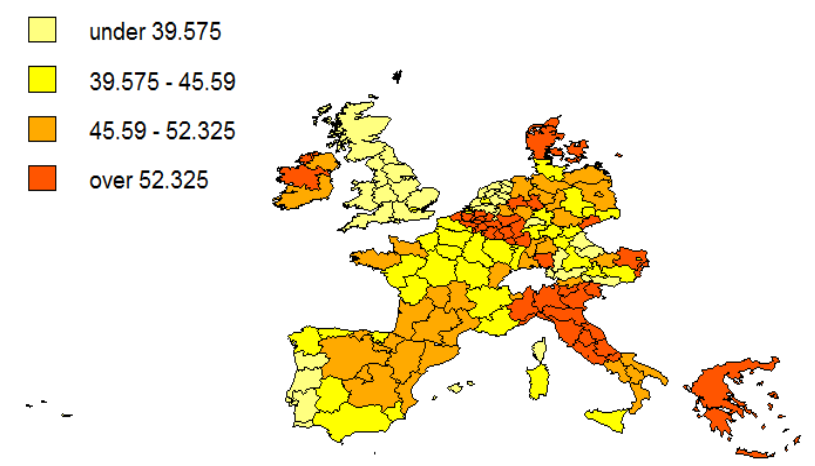

b) Moran Scatterplot 1999

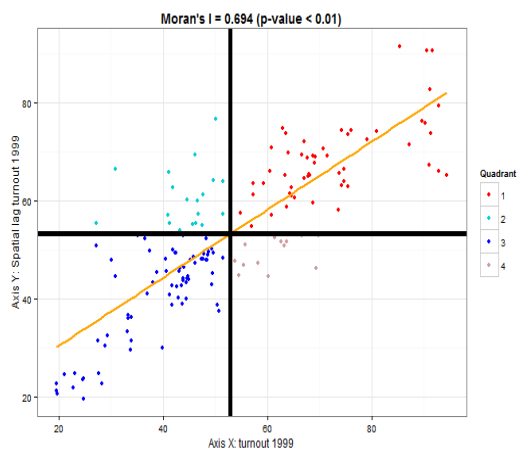

d) Moran Scatterplot 2004

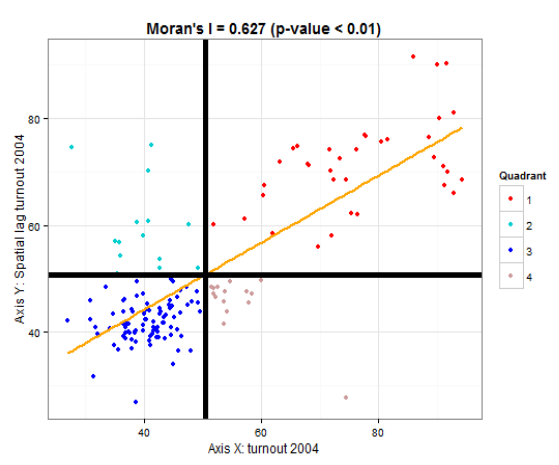

f) Moran Scatterplot

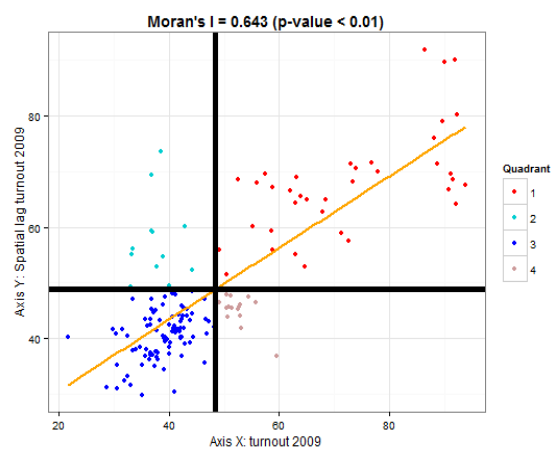

g) Moran Scatterplot 2014

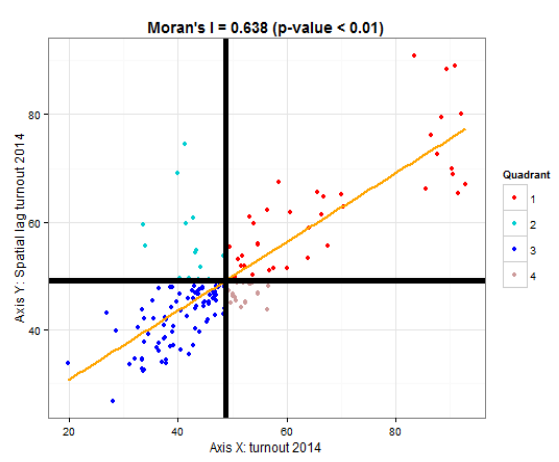


Figure 2. Boxplot turnout

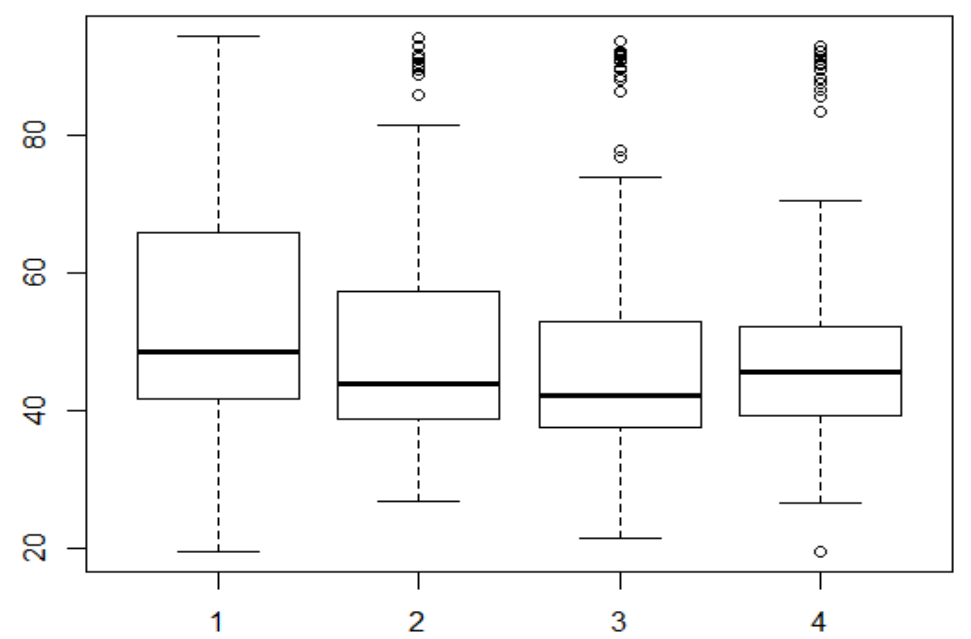

Figure 3: Within country and between countries variance

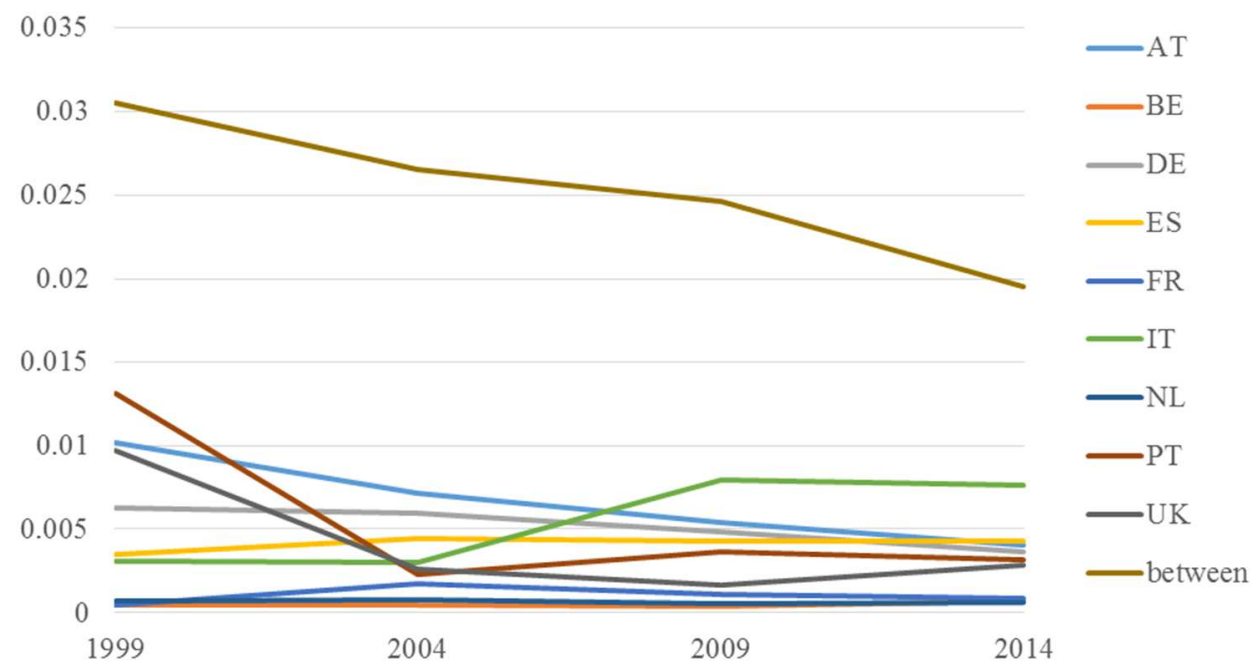

Figure 4: Random effect estimates

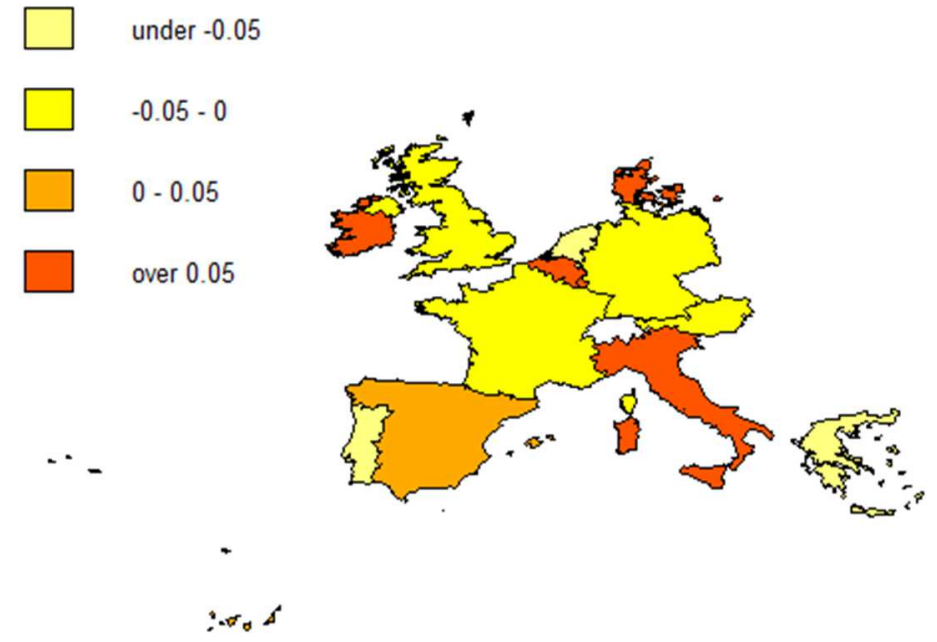


Table 1 - Descriptive statistics

\begin{tabular}{|c|c|c|c|c|c|}
\hline Variable & Mean & Std. dev & Min. & Max. & Territorial level \\
\hline \multicolumn{6}{|c|}{ DEPENDENT } \\
\hline Turnout & 0.5010 & 0.1651 & 0.1960 & 0.9444 & regional \\
\hline \multicolumn{6}{|c|}{ INST } \\
\hline Compulsory voting & 0.08333 & 0.2767 & 0 & 1.0000 & national \\
\hline Weekday vote & 0.1715 & 0.3772 & 0 & 1.0000 & national \\
\hline \multicolumn{6}{|c|}{ SOCEC } \\
\hline $\log ($ per capita GDP) & 10.070 & 0.2715 & 9.367 & 11.130 & regional \\
\hline Employment protection & 2.5920 & 0.7121 & 1.2700 & 4.5830 & national \\
\hline Unemployment & 0.4038 & 0.1279 & 0.0410 & 0.7540 & regional \\
\hline $\log ($ Density $)$ & 5.2480 & 1.0786 & 3.109 & 8.8990 & regional \\
\hline Dependency ratio & 0.9301 & 0.2549 & 0.3952 & 2.0510 & regional \\
\hline \multicolumn{6}{|c|}{ DOMESTIC POLITICS } \\
\hline Herfindhal_gov & 0.7006 & 0.2329 & 0.1810 & 1.0000 & National \\
\hline Herfindhal_opp & 0.5085 & 0.1667 & 0.2199 & 0.8554 & National \\
\hline Effective number of parties & 4.804 & 1.6648 & 2.640 & 10.040 & National \\
\hline Protest vote & 0.1202 & 0.1323 & -0.1726 & 0.3975 & National \\
\hline \multicolumn{6}{|c|}{$\mathbf{E U}$} \\
\hline Objectivel regions & 0.2548 & 0.4361 & 0 & 1.0000 & Regional \\
\hline Trust EU & 4.5070 & 0.6982 & 2.5570 & 7.0000 & Regional \\
\hline
\end{tabular}


Table 2 - Estimation results, multilevel model

\begin{tabular}{|c|c|c|c|c|c|c|c|c|c|c|c|c|}
\hline Groups & Model 1 & & Model 2 & & Model 3 & & Model 3(a) & & Model 4 & & Model 4(a) & \\
\hline \multicolumn{13}{|c|}{ Random effects } \\
\hline Country & $\begin{array}{r}0.0096 \\
(0.0982)\end{array}$ & $* * *$ & $\begin{array}{r}0.0142 \\
(0.1190)\end{array}$ & $* * *$ & $\begin{array}{r}0.0113 \\
(0.1063)\end{array}$ & $* * *$ & $\begin{array}{r}0.0112 \\
(0.1059)\end{array}$ & $* * *$ & $\begin{array}{r}0.0106 \\
(0.1031)\end{array}$ & $* * *$ & $\begin{array}{l}0.0108 \\
(0.104)\end{array}$ & $* * *$ \\
\hline \multirow[t]{2}{*}{ Year } & 0.0004 & $* * *$ & 0.0009 & $* * *$ & 0.0012 & $* * *$ & 0.0009 & $* * *$ & 0.0012 & $* * *$ & 0.0009 & $* * *$ \\
\hline & $(0.0193)$ & & $(0.0304)$ & & $(0.0342)$ & & $(0.0294)$ & & $(0.0346)$ & & $(0.0298)$ & \\
\hline \multirow{2}{*}{ Residual } & 0.0055 & & 0.0051 & & 0.0049 & & 0.0049 & & 0.0049 & & 0.0049 & \\
\hline & $(0.0743)$ & & $(0.0714)$ & & $(0.0703)$ & & $(0.0701)$ & & $(0.0702)$ & & $(0.0700)$ & \\
\hline$\hat{\rho}_{\text {country }}$ & 0.6193 & & 0.7030 & & 0.6494 & & 0.6588 & & 0.6347 & & 0.6506 & \\
\hline \multirow[t]{2}{*}{$\hat{\rho}_{\text {year }}$} & 0.0258 & & 0.0445 & & 0.0690 & & 0.0529 & & 0.0718 & & 0.0542 & \\
\hline & & & & & Fixed effects & & & & & & & \\
\hline \multirow[t]{2}{*}{ Intercept } & 0.4804 & $* * *$ & 0.1755 & & 0.3038 & & 0.1477 & & 0.2528 & & 0.1123 & \\
\hline & $(0.0383)$ & & $(0.1912)$ & & $(0.1942)$ & & $(0.1878)$ & & $(0.199)$ & & $(0.1928)$ & \\
\hline \multirow[t]{2}{*}{ Weekday vote } & -0.0486 & & -0.009 & & -0.0137 & & -0.0077 & & -0.013 & & -0.0077 & \\
\hline & $(0.0533)$ & & $(0.0598)$ & & $(0.0566)$ & & $(0.0562)$ & & $(0.0558)$ & & $(0.0557)$ & \\
\hline \multirow[t]{2}{*}{ Compulsory voting } & 0.327 & $* * *$ & 0.3602 & $* * *$ & 0.3574 & $* * *$ & 0.3384 & $* * *$ & 0.3605 & $* * *$ & 0.341 & $* * *$ \\
\hline & $(0.07)$ & & $(0.084)$ & & $(0.0761)$ & & $(0.0759)$ & & $(0.0741)$ & & $(0.0747)$ & \\
\hline \multirow[t]{2}{*}{$\log (G D P$ per capita $)$} & & & 0.0121 & & 0.0074 & & 0.0064 & & 0.0081 & & 0.0068 & \\
\hline & & & $(0.0173)$ & & $(0.0172)$ & & $(0.017)$ & & $(0.0172)$ & & $(0.0171)$ & \\
\hline \multirow[t]{2}{*}{ Unemployment } & & & -0.0494 & & -0.0743 & * & -0.0523 & & -0.0701 & * & -0.0492 & \\
\hline & & & $(0.0363)$ & & $(0.0362)$ & & $(0.0359)$ & & $(0.0362)$ & & $(0.0359)$ & \\
\hline \multirow[t]{2}{*}{ Employment protection } & & & 0.0626 & $* * *$ & 0.0471 & $* * *$ & 0.0588 & $* * *$ & 0.0504 & $* * *$ & 0.0615 & $* * *$ \\
\hline & & & $(0.0238)$ & & $(0.0231)$ & & $(0.023)$ & & $(0.0232)$ & & $(0.0232)$ & \\
\hline \multirow[t]{2}{*}{ Log(Density) } & & & -0.0057 & & -0.005 & & -0.0048 & & -0.0066 & & -0.0061 & \\
\hline & & & $(0.0041)$ & & (0.004) & & $(0.004)$ & & $(0.0042)$ & & $(0.0042)$ & \\
\hline \multirow[t]{2}{*}{ Dependency ratio } & & & 0.0709 & $* * *$ & 0.0668 & $* * *$ & 0.0737 & $* * *$ & 0.0676 & $* * *$ & 0.0742 & $* * *$ \\
\hline & & & $(0.0166)$ & & $(0.0166)$ & & $(0.0163)$ & & $(0.0166)$ & & $(0.0163)$ & \\
\hline \multirow[t]{2}{*}{ Herfindhal_gov } & & & & & -0.0891 & $* *$ & & & -0.089 & $* *$ & & \\
\hline & & & & & $(0.0301)$ & & & & $(0.0301)$ & & & \\
\hline \multirow[t]{2}{*}{ Herfindhal_opp } & & & & & 0.0388 & & & & 0.0436 & & & \\
\hline & & & & & $(0.0361)$ & & & & $(0.0361)$ & & & \\
\hline \multirow[t]{2}{*}{ Effective number of parties } & & & & & & & 0.0189 & $* * *$ & & & 0.0184 & $* * *$ \\
\hline & & & & & & & $(0.0048)$ & & & & $(0.0048)$ & \\
\hline \multirow[t]{2}{*}{ Protest vote } & & & & & 0.1159 & $* * *$ & 0.0527 & $* *$ & 0.1211 & $* * *$ & 0.0572 & $* *$ \\
\hline & & & & & $(0.0272)$ & & $(0.0261)$ & & $(0.0275)$ & & $(0.0266)$ & \\
\hline \multirow[t]{2}{*}{ Trust_EU } & & & & & & & & & 0.009 & & 0.007 & \\
\hline & & & & & & & & & $(0.0068)$ & & $(0.0068)$ & \\
\hline \multirow[t]{2}{*}{ Objectivel regions } & & & & & & & & & -0.0072 & & -0.0054 & \\
\hline & & & & & & & & & $(0.0071)$ & & $(0.0071)$ & \\
\hline AIC & -1403.65 & & -1434.382 & & -1448.56 & & -1456.354 & & -1447.329 & & -1453.994 & \\
\hline
\end{tabular}

*Significant at $1 \%$, ${ }^{* *}$ significant at $5 \%,{ }^{* *}$ significant at $10 \%$. Standard error in brackets. 
Table 3 - Estimation results, OLS with country dummies

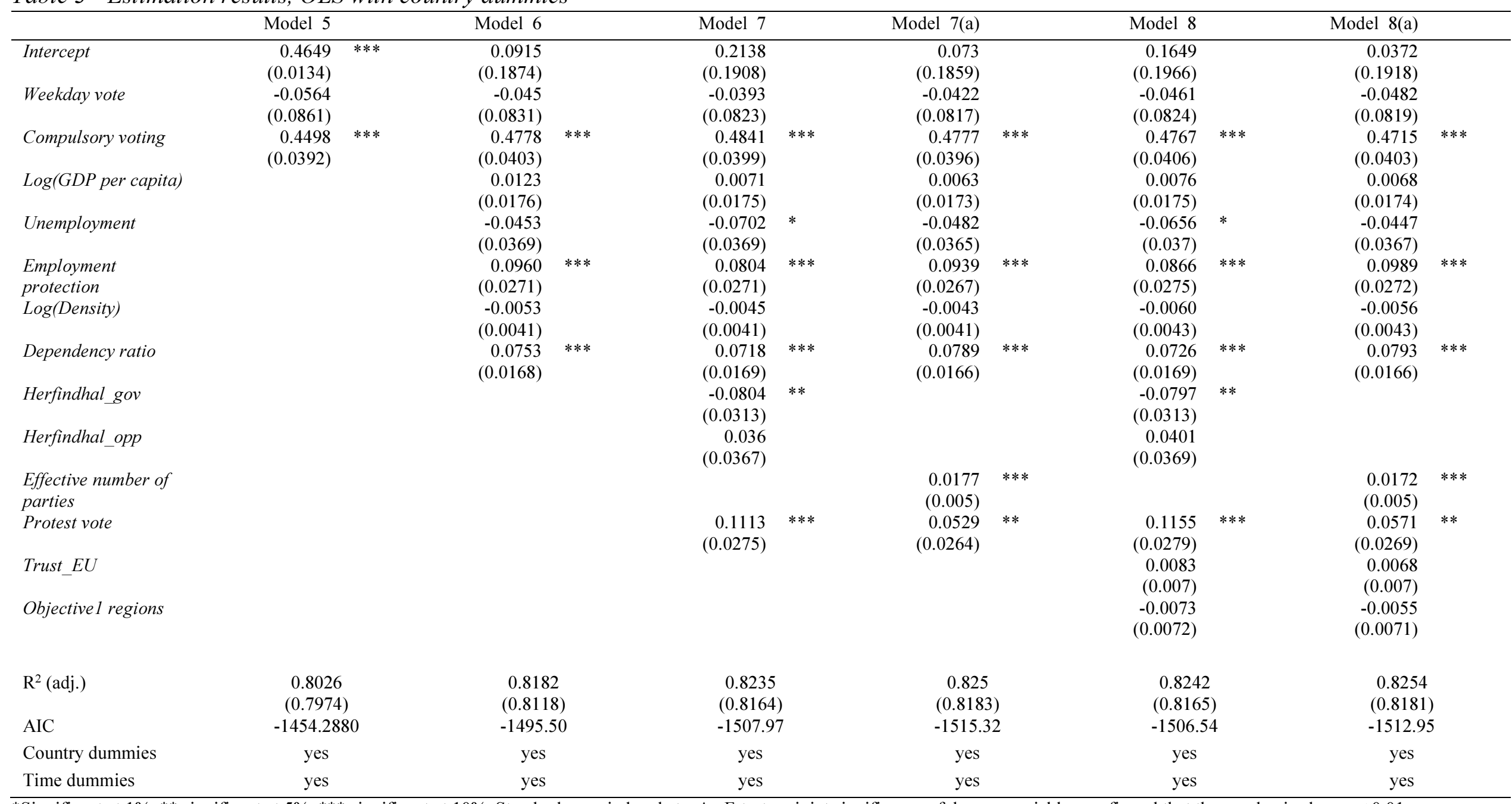

*Significant at $1 \%, * *$ significant at $5 \%, * * *$ significant at $10 \%$. Standard error in brackets. An F-test on joint significance of dummy variables confirmed that the p-value is always $<0.01$. 


\section{References}

Allison, P. D. (2009), Fixed Effects Regression Models, Thousand Oaks, CA: Sage Publications.

Anselin L. (1988). Spatial Econometrics: Methods and Models, Kluwer Academic Publishers, Dordrecht.

Anselin L. (2003). Spatial Externalities, Spatial Multipliers and Spatial Econometrics, International Regional Science Review, 26, 153-166.

Anselin L., Rey S. (1991). Properties of Tests for Spatial Dependence in Linear Regression Models, Geographical Analysis, 23, 112-131.

Beck, T., Clarke, G., Groff, A., Keefer, P. and Walsh, P. (2001). New Tools in Comparative Political Economy: The Database of Political Institutions. World Bank Economic Review $15,1,165-176$.

Bendor, J., Diermeier, D., Ting. M. (2003). A Behavioral Model of Turnout. American Political Science Review, 97, 2: 261-80.

Blais, A. (2000). To Vote or Not To Vote? The Merits and Limits of Rational Choice, Pittsburgh, University of Pittsburgh Press.

Blais, A., Carty, R.K. (1990). Does Proportional Representation Foster Voter Turnout? European Journal of Political Research, 18, 167-181.

Blais, A., Dobrzynska, A. (1998). Turnout in Electoral Democracies. European Journal of Political Research 33, 239-261.

Blondel, J., Sinnott, R., Svensson, P. (1997). Representation and Voter Participation. European Journal of Political Research, 32, 243-272.

Burden, B.C, Wichowsky, A. (2012) Unemployment and Voter Turnout. APSA 2012 Annual Meeting Paper

Cho, W.K.T., Rudolph, T.J. (2008). Emanating Political Participation: Untangling the Spatial Structure behind Participation. British Journal of Political Science, 38, $273-89$.

De Vreese, C., Banducci, S.A., Semetko, H.A., Boomgaarden, H.G. (2006). The News Coverage of the 2004 European Parliamentary Election Campaign in 25 Countries. European Union Politics, 7, 477-504.

Dall'erba S. (2005). Distribution of Regional Income and Regional Funds in Europe 19891999: An Exploratory Spatial Data Analysis, The Annals of Regional Science, 39, 121148.

van der Eijk, C., Franklin, M. (1996). Choosing Europe? The European Electorate and National Politics in the Face of Union, Ann Arbor, University of Michigan Press.

Ertur C., Le Gallo J., Baumont C. (2006). The European Regional Convergence Process, 19801995: Do Spatial Regimes and Spatial Dependence Matter? International Regional Science Review, 29, 3-34.

Florax R.J.G.M., Folmer H. (1992). Specification and Estimation of Spatial Linear Regression Models, Regional Science and Urban Economics, 22, 405-432.

Fornos C.A., Power T.J., Garand J.C. (2004) Explaining Voter Turnout in Latin America, 1980 to 2000. Comparative Political Studies, 37, 8, 909-40.

Fowel, J.H. (2006). Habitual voting and behavioral turnout. Journal of Politics, 68, 2: pp. 335344.

Franklin, M.N., (2004). Voter Turnout and the Dynamics of Electoral Competition in Established Democracies since 1945. Cambridge University Press, Cambridge.

Franklin, M. (2002). Electoral Participation, in Leduc, L. et al. (eds.), Comparing Democracies: New Challenges in the Study of Elections and Voting, Sage, London, 148-168. 
Gallagher, M. (2015). Electoral system website, on line appendix of Gallagher, M. and Mitchell, P. (2008) The Politics of Electoral Systems, Oxford University Press. http://www.tcd.ie/Political_Science/staff/michael_gallagher/ElSystems/

Geys, B. (2006) Explaining Voter Turnout: A Review of Aggregate-Level Research, Electoral Studies, 25, 637-663.

Gregory, T. Patuelli R. (2015). Demographic Ageing and the Polarization of Regions - An Exploratory Space-Time Analysis, Environment and Planning A, 47, 1192-210.

Hix, S. Marsh, M. (2011). Second-Order Effects plus Pan-European Political Swings: An Analysis of European Parliament Elections across Time. Electoral Studies, 30, 4-15.

Hix, S., Noury, A. and Roland, G. (2007). Democratic Politics in the European Parliament, Cambridge, Cambridge University Press.

Holbot, S.B. (2012). Citizen Satisfaction with Democracy in the European Union. Journal of Common Market Studies, 50, S1, 88-105.

Hox, J. J. (2010). Multilevel Analysis. Techniques and Applications. 2. ed. New York, NY: Routledge (Quantitative methodology series).

Jackman, R.W. (1987). Political Institutions and Voter Turnout in the Industrial Democracies. American Political Science Review, 81, 2, 405-423.

Jackman, R.W., Miller, R.A. (1995). Voter Turnout in the Industrial Democracies during the 1980s. Comparative Political Studies 27, 4, 467-492.

Kostadinova, T. (2003). Voter Turnout Dynamics in Post-Communist Europe. European Journal of Political Research, 42,6, 741-59.

Le Gallo, J., Ertur C. (2003). Exploratory spatial data analysis of the distribution of regional per capita GDP in Europe, 1980-1995. Papers in Regional Science, 82:175-201.

Lipset, S. M. (1981). Political Man: The Social Bases of Politics. Baltimore, The Johns Hopkins University Press.

Maas, C. J. M. and Hox, J. J. (2005), Sufficient sample sizes for multilevel modeling, Methodology, 1, 86-92.

Marsh, M. (1998). Testing the Second-Order Election Model after Four European Elections. British Journal of Political Science, 28, 4, 591-607.

Mattila, M. (2003). Why Bother? Determinants of Turnout in the European Elections. Electoral Studies, 22, 449-468.

Moran P. A. P. (1950). Notes on Continuous Stochastic Phenomena, Biometrika, 37, 17-23.

O'Connell, A.A., McCoach, D.B. (2008). Multilevel modelling of educational data. Charlotte. NC. Informational Age Publishing.

Oliver, J. E. (2000). City Size and Civic Involvement in Metropolitan America. American Political Science Review, 94, 361-373.

Orford, S. (2000) "Modelling spatial structures in local housing market dynamics: A multilevel perspective", Urban Studies, 37(9), 1643-1671.

Oppenhuis, E. (1995). Voting Behaviour in Europe. Amsterdam, Het Spinhius.

Overbye, E. (1995). Making a Case for the Rational, Self-regarding 'Ethical' Voter and Solving the 'Paradox of not Voting' in the Process, European Journal of Political Research, 27, 269-296.

Radcliff B., Davis P. (2000). Labour Organization and Electoral Participation in Industrial Democracies. American Journal of Political Science, 44, 132-41.

Radcliff, B. (1992). The Welfare State, Turnout, and the Economy: A Comparative Analysis. American Political Science Review, 86, 444-54.

Radcliff, B. (1994). Reward without Punishment: Economic Conditions and the Vote. Political Research Quarterly, 47, 21-31. 
Reif, K., Schmitt, H. (1980). Nine Second-order National Elections. A Conceptual Framework for the Analysis of European Election Results. European Journal of Political Research, 8, 3-44.

Ricciuti, R. (2004). Political Fragmentation and Fiscal Outcomes. Public Choice, 118, 365388.

Rosenstone, S. (1982). Economic Adversity and Voter Turnout. American Journal of Political Science, 26, 1, 25-46.

Rosenstone, S.J., Wolfinger, R.E. (1978). The Effect of Registration Laws on Voter Turnout. American Political Science Review, 72, 1, 22-45.

Schmitt, H., Mannheimer, R. (1991). About Voting and Non-Voting in the European Elections of June 1989. European Journal of Political Research, 19, 31-54.

Snijders, T. A.B. and Bosker, R.J., (1999) Multilevel Analysis, Sage, London.

Sundstrom, A, Stockemer, D. (2015). Regional Variation in Voter Turnout in Europe: The Impact of Corruption Perceptions. Electoral Studies, 40, 158-169

Verba, S., Schlozman, K.L., Henry E. Brady, H.E. (1995). Voice and Equality: Civic Voluntarism in American Politics. Cambridge, MA: Harvard University Press. 


\section{APPENDIX}

Table A1: correlation matrix

\begin{tabular}{|c|c|c|c|c|c|c|c|c|c|c|c|c|c|c|}
\hline & Turnout & $\begin{array}{c}\text { Weekday } \\
\text { vote }\end{array}$ & $\begin{array}{l}\text { Comp. } \\
\text { voting }\end{array}$ & $\begin{array}{c}\log (G D P \\
\text { per } \\
\text { capita) }\end{array}$ & Unempl. & $\begin{array}{c}\text { Employment } \\
\text { protection }\end{array}$ & $\log ($ Density $)$ & $\begin{array}{l}\text { Dep. } \\
\text { ratio }\end{array}$ & $\begin{array}{l}\text { Herfindhal } \\
\text { gov }\end{array}$ & $\begin{array}{l}\text { Herfindhal } \\
\quad \text { opp }\end{array}$ & $\begin{array}{c}\text { Effective } \\
\text { number of } \\
\text { parties }\end{array}$ & $\begin{array}{c}\text { Protest } \\
\text { vote }\end{array}$ & $\begin{array}{c}\text { Trust } \\
E U\end{array}$ & $\begin{array}{l}\text { Ob. } 1 \\
\text { regions }\end{array}$ \\
\hline Turnout & 1.0000 & & & & & & & & & & & & & \\
\hline Weekday vote & -0.3552 & 1.0000 & & & & & & & & & & & & \\
\hline Compulsory voting & 0.6945 & -0.1372 & 1.0000 & & & & & & & & & & & \\
\hline $\begin{array}{l}\log (G D P \text { per } \\
\text { capita })\end{array}$ & 0.0184 & 0.1236 & 0.1053 & 1.0000 & & & & & & & & & & \\
\hline Unemployment & 0.2201 & -0.3103 & 0.1404 & -0.3132 & 1.0000 & & & & & & & & & \\
\hline $\begin{array}{l}\text { Employment } \\
\text { protection }\end{array}$ & -0.1326 & 0.0825 & -0.0799 & 0.0072 & 0.1192 & 1.0000 & & & & & & & & \\
\hline $\log ($ Density) & -0.0361 & 0.1921 & 0.1499 & 0.4253 & 0.1444 & -0.0187 & 1.0000 & & & & & & & \\
\hline $\begin{array}{l}\text { Dependency } \\
\text { ratio }\end{array}$ & 0.0823 & -0.2304 & -0.0865 & 0.0373 & 0.1481 & 0.1115 & -0.2830 & 1.0000 & & & & & & \\
\hline Herfindhal_gov & -0.1013 & 0.1465 & -0.0667 & 0.0331 & -0.2591 & 0.3283 & -0.0438 & 0.0852 & 1.0000 & & & & & \\
\hline Herfindhal_opp & -0.0271 & 0.0642 & -0.0059 & 0.0197 & -0.2380 & 0.3646 & -0.0194 & 0.0293 & 0.8538 & 1.0000 & & & & \\
\hline $\begin{array}{l}\text { Effective number of } \\
\text { parties }\end{array}$ & 0.0605 & -0.1215 & -0.0583 & -0.2806 & -0.0651 & -0.2071 & -0.0235 & -0.2729 & -0.0508 & 0.1855 & 1.0000 & & & \\
\hline Protest vote & -0.0368 & 0.0053 & -0.0407 & -0.0524 & -0.1355 & 0.4895 & -0.0733 & 0.0097 & 0.7203 & 0.8457 & 0.2974 & 1.0000 & & \\
\hline Trust_EU & 0.3878 & -0.2326 & 0.1806 & 0.0950 & 0.2088 & 0.0374 & 0.1810 & -0.0561 & -0.0004 & -0.0183 & -0.0213 & -0.0186 & 1.0000 & \\
\hline Objectivel regions & -0.0478 & 0.0560 & 0.0100 & 0.0289 & 0.1226 & 0.0878 & 0.0571 & 0.0896 & -0.1811 & -0.1716 & -0.2282 & -0.1772 & 0.0135 & 1.0000 \\
\hline
\end{tabular}

